\title{
Cross-sectional study of male sexual function in bariatric patients
}

\author{
Michat R. Janik ${ }^{1}$, Ilona Bielecka ${ }^{1}$, Andrzej Kwiatkowski ${ }^{1}$, Piotr E. Janik ${ }^{2}$, Thomas Drazba ${ }^{1}$, Jan Bujok ${ }^{1}$, \\ Edward Stanowski ${ }^{1}$, Krzysztof Paśnik ${ }^{1}$ \\ ${ }^{1}$ Department of General, Oncologic, Metabolic and Thoracic Surgery, Military Institute of Medicine, Warsaw, Poland \\ ${ }^{2}$ Medical Centre for Postgraduate Education, Warsaw, Poland
}

Videosurgery Miniinv 2016; 11 (3): 171-177

DOI: $10.5114 /$ wiitm.2016.62135

\begin{abstract}
Introduction: Obesity is associated with numerous comorbidities and affects various aspects of life, including sexual functioning. Bariatric surgery is an effective treatment for obese people. Male sexual function after bariatric surgery is not well known.

Aim: To compare male sexual function and sexual quality of life after surgical weight loss with controls seeking bariatric surgery.

Material and methods: International Index of Erectile Function and Sexual Quality of Life-Male (SQoL-M) questionnaires were administered by e-mail to 152 men who had undergone weight-loss surgery. The control group consisted of 44 obese men who completed the questionnaires during their preoperative evaluation.

Results: Fifty-six percent of men in the control group and 20\% of men in the postoperative group reported erectile dysfunction (ED) $(O R=5.1 ; 95 \% \mathrm{Cl}: 1.6-16.0, p=0.005)$. The median (Q1, Q3) total International Index of Erectile Function (IIEF) score did not show a significant difference between the control $(62.0(37.5,66.5))$ and postoperative groups (67.0 (57.0, 70.0)). However, median scores in domains of erectile function (EF), sexual desire (SD), and overall satisfaction (OS) were significantly higher in the postoperative group. The median SQoL-M was significantly higher $(81.8(51.5,89.4)$ vs. $88.6(84.8,90.9) ; p<0.05)$ in the postoperative group.

Conclusions: A lower prevalence of erectile dysfunction and better sexual quality of life were observed in the patients after surgical weight loss. The improvement in male sexual function may be considered as an advantage of bariatric surgery.
\end{abstract}

Key words: obesity, bariatric surgery, male sexual function, erectile function.

\section{Introduction}

The prevalence of obesity among men increased in Poland over the last decade [1]. This trend is observed in the majority of Western countries [2]. Obesity is associated with numerous comorbidities and affects various aspects of life, including sexual functioning. A link between obesity and female sexual dysfunction is well established. In the case of men, research proved impaired sexual function in overweight and obese subjects [3]. As a result of the presence of central obesity, hypertension, diabetes, insulin resistance and hormone disorders, this population is more prone to experience erectile dysfunction (ED) $[4,5]$. Erectile dysfunction is defined as the inability to achieve and maintain an erection sufficient to permit satisfactory sexual intercourse. It may result from psychological, neurologic, hormonal, arterial or cavernosal impairment, or from a combination of these factors. This condition results in poor quality of male sexual life [6]. In

\section{Address for correspondence}

Michał R. Janik MD, Department of General, Oncologic, Metabolic and Thoracic Surgery, Military Institute of Medicine, 128 Szaserów St, 04-141 Warsaw, Poland, phone: +48 602780 960, e-mail: janiken@gmail.com 
the case of obese patients, multiple factors could play a role in male sexual dysfunction, including medical treatment, which can interfere with sexual function, vascular damage due to uncontrolled diabetes or hypertension and lack of self-esteem [4]. Bariatric surgery is an effective treatment option for obese people [7, 8]. At present, laparoscopic sleeve gastrectomy (LSG) and laparoscopic Roux-en-Y gastric bypass (LRYGB) are the most popular types of bariatric operations [9, 10]. In LSG, $75-80 \%$ of the greater curvature is resected, forming a narrow, sleeve-shaped stomach. The procedure was originally described as a restrictive part of biliopancreatic diversion with duodenal switch [11]. In the case of LRYGB, a small pouch is created, dividing the stomach and connected to the distal part of the small jejunum creating the Roux-en-Y anastomosis [12]. The procedures are equally effective in the case of weight loss, but LRYGB seems to be more effective in resolving comorbidities $[7,8]$. The weight loss after bariatric surgery leads to the normalization of hormone levels and resolution of comorbidities, especially hypertension and diabetes [5]. In the majority of patients, there is a reduction of antihypertensive and diabetic drug use in the post-operative period [13]. An increase in quality of life is also observed [14]. So, if the risk factors of ED are removed due to surgery, is there a chance to reduce the prevalence of ED in post-bariatric patients?

\section{Aim}

The aim of this study was to compare male sexual function and sexual quality of life after surgical weight loss with the control group seeking bariatric surgery.

\section{Material and methods}

This cross-sectional study was performed in our Department of Surgery between January 2015 and May 2015. The postoperative group comprised 152 men 12-18 months after undergoing bariatric surgery, either LSG or LRYGB. The control group consisted of 44 obese men seeking bariatric surgery. Medical indications for bariatric surgery included body mass index (BMI) $35-39.9 \mathrm{~kg} / \mathrm{m}^{2}$ associated with comorbidities or $>40 \mathrm{~kg} / \mathrm{m}^{2}$. All participants completed a demographic questionnaire and a health history checklist. In the postoperative group, the data were collected using an emailed questionnaire. The con- trol group was asked to complete the questionnaires during their preoperative evaluation in an outpatient clinic. The study was approved by the Institutional Review Board (IRB), and informed consent was obtained from the patients. All patients met the Interdisciplinary European Guidelines on Metabolic and Bariatric Surgery criteria for bariatric surgery [15]. The exclusion criteria were as follows: no sexual activity in the past 4 weeks, history of drug use such as antidepressants and psychotropic drugs. None of the men were taking phosphodiesterase type- 5 inhibitors.

Patients in both groups were asked to complete the International Index of Erectile Function (IIEF) and Sexual Quality of Life-Male (SQoL-M) questionnaires, which are described in detail in Tables I and II.

The IIEF was developed and validated in 19961997 as an adjunct to the sildenafil clinical trial program [16-18]. In 1999, the IIEF was recommended by the 1st International Consultation on Erectile Dysfunction, sponsored by the World Health Organization, as the efficacy endpoint of choice for clinical trials in ED [19]. The IIEF is currently available in over 32 languages world-wide, including Polish. IIEF is the 'gold standard' in treatment outcome measures for clinical trials in ED. The IIEF is composed of 15 items investigating 5 dimensions: erectile function (six items), orgasmic function (two items), sexual desire (two items), intercourse satisfaction (three items), and overall satisfaction (two items). Erectile dysfunction items assess the degree of ED. According to the scoring there are five categories of ED: severe erectile dysfunction (1-10 points), moderate dysfunction (11-16), mild to moderate dysfunction (17-21), mild dysfunction (22-25), and no dysfunction (26-30). In the other domains, higher scores reflect less dysfunction $[16,17,20]$. The $2^{\text {nd }}$ version of the IIEF was used in the study. The total IIEF cutoff score for a diagnosis of ED was $<26.0$.

The SQoL-M is an 11-item self-report questionnaire developed by Abraham et al. [21].

It assesses the impact of sexual dysfunction on a man's sexual quality of life. Each question is scored on a six-point scale ranging from completely agree to completely disagree. A higher total score reflects a better sexual quality of life. Demographic characteristics of age, weight, height, comorbidities, marital status, smoking status and home town were collected using an additional questionnaire. 
Table I. Structure of International Index of Erectile Function (IIEF)

\begin{tabular}{|c|c|c|c|c|c|c|}
\hline Dimensions & $\begin{array}{l}\text { Number } \\
\text { of items }\end{array}$ & $\begin{array}{l}\text { Extension } \\
\text { of the } \\
\text { scoring scale }\end{array}$ & $\begin{array}{l}\text { Control } \\
\text { group }\end{array}$ & $\begin{array}{l}\text { Postoperative } \\
\text { group }\end{array}$ & $P$-value & Scoring \\
\hline \multirow[t]{5}{*}{ Erectile function (EF) } & \multirow[t]{5}{*}{6} & \multirow[t]{5}{*}{$1-30$} & \multirow[t]{5}{*}{$24.5(13.5,29.0)$} & \multirow[t]{5}{*}{$28.5(26.0,30.0)$} & \multirow[t]{5}{*}{0.011} & $\begin{array}{c}\text { 1-10: severe erectile } \\
\text { dysfunction }\end{array}$ \\
\hline & & & & & & $\begin{array}{l}\text { 11-16: moderate } \\
\text { dysfunction }\end{array}$ \\
\hline & & & & & & $\begin{array}{l}\text { 17-21: mild } \\
\text { to moderate } \\
\text { dysfunction }\end{array}$ \\
\hline & & & & & & $\begin{array}{l}\text { 22-25: mild } \\
\text { dysfunction }\end{array}$ \\
\hline & & & & & & $\begin{array}{l}\text { 26-30: no } \\
\text { dysfunction }\end{array}$ \\
\hline Orgasmic function (OF) & 2 & $0-10$ & $10(9,10)$ & $10(8,10)$ & 0.548 & \multirow{5}{*}{$\begin{array}{c}\text { Higher score = less } \\
\text { dysfunction }\end{array}$} \\
\hline Sexual desire (SD) & 2 & $2-10$ & $8(6,8)$ & $8.5(8.0,10)$ & 0.029 & \\
\hline Intercourse satisfaction (IS) & 3 & $0-15$ & $11.5(5.5,12.0)$ & $10.5(9.0,11.0)$ & 0.045 & \\
\hline Overall satisfaction (OS) & 2 & $2-10$ & $8(6,9)$ & $10(7,10)$ & 0.018 & \\
\hline Total IIEF & 15 & $5-75$ & $62.0(37.5,66.5)$ & $67.0(57.0,70.0)$ & 0.076 & \\
\hline
\end{tabular}

Table II. Structure of Sexual Quality of Life-Male Questionnaire (SQOL-M)

\begin{tabular}{|lcccc|}
\hline Items (median, Q1, Q3) & $\begin{array}{c}\text { Max } \\
\text { pts. }\end{array}$ & $\begin{array}{c}\text { Control } \\
\text { group }\end{array}$ & $\begin{array}{c}\text { Postoperative } \\
\text { group }\end{array}$ & $\begin{array}{c}\text { P-value } \\
\text { 1. When I think about my sexual life, I feel frustrated* }\end{array}$ \\
\hline 2. When I think about my sexual life, I feel depressed & 6 & $5(3,6)$ & $6(5,6)$ & 0.031 \\
\hline 3. When I think about my sexual life, I feel like less of a man & 6 & $6(3,6)$ & $6(4,6)$ & 0.561 \\
\hline 4. I have lost confidence in myself as a sexual partner* & 6 & $5(3,6)$ & $6(5,6)$ & 0.042 \\
\hline 5. When I think about my sexual life, I feel anxious* & 6 & $5(3,6)$ & $6(5,6)$ & 0.014 \\
\hline 6. When I think about my sexual life, I feel angry & 6 & $6(3,6)$ & $6(5,6)$ & 0.144 \\
\hline 7. I worry about the future of my sexual life* & 6 & $5(3,6)$ & $6(5,6)$ & 0.001 \\
\hline $\begin{array}{l}\text { 8. When I think about my sexual life, I am embarrassed* } \\
\text { 9. When I think about my sexual life, I feel guilty* }\end{array}$ & 6 & $5.5(3,6)$ & $6(6,6)$ & 0.011 \\
\hline $\begin{array}{l}\text { 10. When I think about my sexual life, I worry that my partner feels } \\
\text { hurt or rejected* }\end{array}$ & 6 & $6(4,6)$ & $6(6,6)$ & 0.023 \\
\hline \begin{tabular}{l} 
11. When I think about my sexual life, I feel like I have lost something* \\
\hline Total score*
\end{tabular} & 6 & $5(3,6)$ & $6(6,6)$ & 0.002 \\
\hline
\end{tabular}

*Significant differences at $p<0.05$ between groups.

\section{Statistical analysis}

Statistical analyses were conducted using SAS software, University Edition Version (SAS Institute Inc., Cary, NC, USA). Fisher's exact test was used to de- termine differences in the prevalence of ED between groups. The unpaired $t$ test and the Mann-Whitney $U$ test were used to assess differences in participants' scores. Pearson's correlation coefficient was used to assess the relationships of body mass index 
(BMI) to IIEF and EF score and of BMI versus SQoL-M total score. Logistic regression was used to measure the relationship between variables and ED diagnosis. Statistical significance was set at $p<0.05$.

\section{Results}

\section{Baseline characteristics}

The survey response rate was $73 \%$ in the control group $(n=32 / 44)$ and $20 \%$ in the postoperative ( $n=30 / 152)$ group. The groups were comparable regarding age and marital status but differed significantly in BMI, comorbidities, home town population and smoking status. The control group reported comorbidities of hypertension and diabetes, whereas

Table III. Sociodemographic characteristics of patients

\begin{tabular}{|c|c|c|}
\hline $\begin{array}{l}\text { Patients' } \\
\text { characteristics }\end{array}$ & $\begin{array}{l}\text { Control group } \\
(n=31 / 32)\end{array}$ & $\begin{array}{c}\text { Postoperative } \\
\text { group }(n=30 / 30)\end{array}$ \\
\hline Age [years] & $42 \pm 8$ & $43 \pm 10$ \\
\hline $\mathrm{BMI}\left[\mathrm{kg} / \mathrm{m}^{2}\right]$ & $48 \pm 10^{*}$ & $29 \pm 2^{*}$ \\
\hline \multicolumn{3}{|l|}{ Comorbidities $(\%)^{\star}$ : } \\
\hline Hypertension & 61 & 10 \\
\hline Diabetes & 26 & 0 \\
\hline \multicolumn{3}{|l|}{ Marital status (\%): } \\
\hline Married & 84 & 83 \\
\hline Divorced & 3 & 7 \\
\hline Concubinage & 6 & 3 \\
\hline Single & 6 & 7 \\
\hline \multicolumn{3}{|l|}{ Smoking status $(\%)^{\star}$ : } \\
\hline Never smoker & 33 & 60 \\
\hline Current smoker & 20 & 30 \\
\hline Former smoker & 47 & 10 \\
\hline \multicolumn{3}{|c|}{ Home town population $(\%)^{\star}$ : } \\
\hline $\begin{array}{l}\text { City }<100,000 \\
\text { inhabitants }\end{array}$ & 34 & 3 \\
\hline $\begin{array}{l}\text { City } 100,00-250,000 \\
\text { inhabitants }\end{array}$ & 3 & 0 \\
\hline $\begin{array}{l}\text { City } 250,000-500,000 \\
\text { inhabitants }\end{array}$ & 7 & 23 \\
\hline $\begin{array}{l}\text { City > } 500000 \\
\text { inhabitants }\end{array}$ & 55 & 73 \\
\hline
\end{tabular}

*Significant differences at $p<0.05$ between groups. the postoperative group reported only hypertension. There were three categories regarding smoking status: never smoked, current smoker and former smoker. The control group had more former smokers (47\% vs. $10 \%)$ and fewer never smokers (33\% vs. $60 \%)$ in the postoperative group. The number of current smokers was comparable. Men in the postoperative group more often lived in large cities (> 250000 inhabitants). In the postoperative group, $44 \%$ underwent LRYGB and 56\% underwent LSG. Patient characteristics are shown in Table III.

\section{Sexual Function and Sexual Quality of Life}

Fifty-six percent of men in the control group and $20 \%$ of men in the postoperative group reported severe to mild ED (Table IV). On the basis of EF scores, sexual dysfunction was diagnosed in $18 / 32$ patients in the control group and $6 / 30$ in the postoperative group. In the case of controls, the odds ratio (OR) for presence of any category of erectile dysfunction was 5.1 (95\% Cl: 1.6-16.0, $p=0.005)$. The median (Q1, Q3) total IIEF score did not show significant differences between the preoperative (62.0 (37.5, $66.5))$ and postoperative groups (67.0 (57.0, 70.0)). However, median scores in the domains of erectile function (EF: 24.5 (13.5, 29.0) vs. 28.5 (26.0, 30.0)); sexual desire (SD: 8.0 (6.0, 8.0) vs. 8.5 (8.0, 10.0)); and overall satisfaction (OS: $8.0(6.0,9.0)$ vs. 10.0 (7.0, 10.0)) were significantly higher in the postoperative group. The intercourse satisfaction (IS: 11.5 $(5.5,12.0)$ vs. $10.5(9.0,11.0))$ was lower in the postoperative group. The orgasmic function (OF) domain did not differ between groups (Table IV).

Table IV. Categories of erectile dysfunction*

\begin{tabular}{|lcc|}
\hline $\begin{array}{l}\text { Categories of } \\
\text { erectile dysfunction, } \\
n(\%)\end{array}$ & $\begin{array}{c}\text { Control group } \\
(N=32)\end{array}$ & $\begin{array}{c}\text { Postoperative } \\
\text { group }(N=30)\end{array}$ \\
\hline $\begin{array}{l}\text { Erectile dysfunction: } \\
\begin{array}{l}\text { Severe erectile } \\
\text { dysfunction }\end{array}\end{array}$ & $5(16)$ & $0(0)$ \\
$\begin{array}{l}\text { Moderate } \\
\text { dysfunction }\end{array}$ & $5(16)$ & $1(3)$ \\
$\begin{array}{l}\text { Mild to moderate } \\
\text { dysfunction }\end{array}$ & $1(3)$ & $2(10)$ \\
\hline $\begin{array}{l}\text { Mild dysfunction } \\
\text { No dysfunction }\end{array}$ & $14(22)$ & $24(80)$ \\
\hline Significant differencesat $p<0.05$ between groups.
\end{tabular}

*Significant differences at $p<0.05$ between groups. 
The median SQoL-M was significantly higher $(81.8(51.5,89.4)$ vs. $88.6(84.8,90.9))$ in the postoperative group. Regarding each item separately, an improvement was observed in 8/11 items (Table II).

There was a strong positive correlation between SQoL-M and total IIEF Score in the preoperative and postoperative group $(r=0.750, p<0.001 ; r=0.490$, $p=0.006$ ). Considering the relation between SQoL-M and $\mathrm{EF}$ score in the control and postoperative group, a significant positive correlation was also present $(r=0.723, p<0.001 ; r=0.593, p<0.001)$. The results did not reveal correlations between BMI and SQoL-M scores, or BMI and IIEF total scores in both groups.

\section{Sexual Function and Sexual Quality of Life adjusted to the type of procedure}

Regarding the type of surgery, no difference was observed in the prevalence of ED between patients after LSG and those after LRYGB (Table V). The median IIEF score in patients after LSG was 27.5 (26.0, 30.0), and in patients after LRYGB it was 29.5 (26.0, $30.0)(p=0.33)$. The total median SQoL-M score in patients after LSG was $88.6(84.8,90.9)$, and in the post-LRYGB group the score was $88.6(84.0,90.9)$ $(p=0.89)$. The results were comparable.

\section{Factors associated with the increased risk of ED diagnosis in IIEF questionnaire}

Data of 62 patients were analyzed in multivariate analysis for factors associated with the increased risk of ED diagnosis. The analysis included the following variables: age, BMI, history of bariatric surgery, type of procedure, history of hypertension, history of diabetes, home town population and smoking status. Only two variables were predictive for risk of ED: age $(\mathrm{OR}=1.09 ; 95 \% \mathrm{Cl}: 1.02-1.20$, $p<0.001)$ and no history of bariatric surgery $(\mathrm{OR}=$ 8.43; 95\% Cl: 2.19-32.42, $p=0.002$ ).

\section{Discussion}

The influence of bariatric surgery on comorbidities raises the hypothesis of low prevalence of ED in post-bariatric patients. The association between hypertension, diabetes and erectile dysfunction is well documented. Also, the side effects of antihypertensive treatment can cause disturbances in erectile function [4]. The question is: if bariatric surgery leads to the resolution of hypertension, improves in-
Table V. Categories of erectile dysfunction adjusted for the type of surgery ${ }^{\text {NS }}$

\begin{tabular}{|lcc|}
\hline $\begin{array}{l}\text { Categories of erectile } \\
\text { dysfunction, } n(\%)\end{array}$ & $\begin{array}{c}\text { LSG } \\
(N=18)\end{array}$ & $\begin{array}{c}\text { LRYGB } \\
(N=12)\end{array}$ \\
\hline $\begin{array}{l}\text { Erectile dysfunction: } \\
\begin{array}{l}\text { Severe erectile } \\
\text { dysfunction }\end{array}\end{array}$ & $0(0)$ & $0(0)$ \\
$\begin{array}{l}\text { Moderate } \\
\text { dysfunction }\end{array}$ & $1(5)$ & $0(0)$ \\
\hline $\begin{array}{l}\text { Mild to moderate } \\
\text { dysfunction }\end{array}$ & $3(17)$ & $0(0)$ \\
\hline $\begin{array}{l}\text { Mild dysfunction } \\
\text { No dysfunction }\end{array}$ & $0(0)$ & $10(83)$ \\
\hline NsNo significant differences between groups.
\end{tabular}

sulin sensitivity and normalizes hormone levels, will it cure ED?

Our study compared the male sexual function and sexual quality of life in patients before and after weight loss surgery. So far, this issue has not been sufficiently explored. The effect of bariatric surgery was established in the case of female patients, whereas in men the issue has not been explored sufficiently [22]. However, considering the high prevalence of erectile dysfunction and low sexual quality of life in obese patients, the problem should not be ignored.

A review of the literature was performed. Articles were identified by searching the PubMed database for the following phrases: "International Index of Erectile Function Questionnaire" and "bariatric surgery". The review revealed only five papers, where the IIEF questionnaire was used to assess sexual function in bariatric patients (Table VI).

Efthymiou et al. assessed the sexual function in 30 male patients. All participants were evaluated using IIEF four times as follows: before surgery, 1 month, 6 months and 1 year after surgery. The authors reported significant improvement in erectile function, desire, contact satisfaction and total satisfaction within 1 year after surgery [23].

Rosenblatt et al. performed a comparative study, where the profile of sexual function was assessed by IIEF. The authors presented the results of 24 men who underwent bariatric surgery, 14 obese and 14 lean controls. The International Index of Erectile Function score revealed no differences; however, the domains of erectile dysfunction and overall satisfaction were better than those in the obese controls. In 
Table VI. Literature review

\begin{tabular}{|c|c|c|c|c|c|c|c|}
\hline \multirow[t]{2}{*}{ Authors (year) } & \multirow[t]{2}{*}{$\begin{array}{c}\text { Surgical } \\
\text { procedures }\end{array}$} & \multicolumn{5}{|c|}{$\begin{array}{l}\text { Changing trends in International Index of Erectile Function } \\
\text { (IIEF) domain scores after bariatric surgery }\end{array}$} & \multirow[t]{2}{*}{$\begin{array}{c}\text { IIEF total } \\
\text { score }\end{array}$} \\
\hline & & $\begin{array}{l}\text { Erectile } \\
\text { function } \\
\text { (EF) }\end{array}$ & $\begin{array}{l}\text { Orgasmic } \\
\text { function } \\
\text { (OF) }\end{array}$ & $\begin{array}{l}\text { Sexual } \\
\text { desire } \\
\text { (SD) }\end{array}$ & $\begin{array}{l}\text { Intercourse } \\
\text { satisfaction } \\
\text { (IS) }\end{array}$ & $\begin{array}{l}\text { Overall } \\
\text { satisfaction } \\
\text { (OS) }\end{array}$ & \\
\hline Efthymiou et al. (2015) [21] & RYGB, SG, BPD & $\uparrow$ & - & $\uparrow$ & $\uparrow$ & $\uparrow$ & NA \\
\hline Rosenblatt et al. (2013) [22] & RYGB & $\uparrow$ & - & - & - & $\uparrow$ & - \\
\hline Reis et al. $(2010,2012)[23,24]$ & RYGB & NA & NA & NA & NA & NA & $\uparrow$ \\
\hline Mora et al. (2013) [25] & RYGB, SG & $\uparrow$ & - & $\uparrow$ & - & $\uparrow$ & $\uparrow$ \\
\hline Groutz et al. (2016) [26] & SG & $\uparrow$ & - & - & $\uparrow$ & $\uparrow$ & $\uparrow$ \\
\hline Present study & LRYGB, SG & $\uparrow$ & - & $\uparrow$ & $\downarrow$ & $\uparrow$ & - \\
\hline
\end{tabular}

$B P D$ - biliopancreatic diversion, RYGB - Roux-en-Y gastric bypass, SG - sleeve gastrectomy, NA - not available.

spite of the difference, the results were still lower than in lean controls [24].

The review revealed two papers by Reis et al. based on the same study [25]. In both papers the authors presented the results of a comparative study of 20 obese patients who were randomized for intervention: lifestyle modifications (exercise and diet) for 4 months and subsequently gastric bypass $(n=10)$ and control: follow-up $(n=10)$. All patients filled in the IIEF questionnaire. The authors reported significant improvement in erectile function and sexual quality of life in the intervention group $[25,26]$.

There was a paper published by Mora et al., which was not revealed in the review but in our opinion is worth mentioning. The authors reported the results of 39 men who underwent bariatric surgery. The sexual function was assessed before and one year after surgery. The findings revealed significant improvement in EF, SD and OS scores [27].

In our study, we observed a significantly higher total SQoL-M score in the postoperative group, indicating a better sexual quality of life in patients who underwent bariatric surgery. The prevalence of ED was lower in the postoperative group. The analysis of IIEF domains revealed higher scores in the postoperative group in the case of erectile function, sexual desire and overall satisfaction, which reflects better sexual functioning in these patients. Considering the erectile function, sexual desire and overall satisfaction, the findings are similar to those presented by other authors [23-28]. However, it should be pointed out that our study is the only one where intercourse satisfaction was lower in post-bariatric patients. The
IIEF and SQoL-M scores were not dependent on the type of surgery. Both procedures were equal in terms of ED prevalence. Surprisingly, we did not observe a relationship between the comorbidities, smoking status or home town population and the risk of ED. Our analysis revealed that age and no history of bariatric surgery were factors associated with higher risk of ED in obese patients. Regarding the positive correlation between the IIEF total score and SQoL-M, as well as a strong correlation between the EF total score and SQoL-M score, we conclude that the IIEF and EF scores predict the SQoL-M score.

The findings support the claim that obesity is associated with higher risk of ED and poor sexual quality of life. In our opinion, the low prevalence of ED observed in the postoperative group reflects the improvement in male sexual function after bariatric surgery. The strong positive correlation between SQoL-M and EF score proved that sexual quality of life is dependent on erectile function. Thus, improvement in sexual function should be considered as an additional advantage of surgical weight loss besides its influence on comorbidities.

The study had the following limitations. In our opinion, the number of patients in both groups was relatively small. The sensitive nature of the research subject was responsible for the low compliance in the postoperative group. We do not recommend e-mail as a method of questionnaire application due to the low response rate. The groups were not comparable regarding smoking status and home town population. However, in our study the risk of ED diagnosis was not dependent on smoking 
status or home town population. Another issue is a lack of follow-up in the case of the control group. We also did not collect data regarding the weight loss. In our study we used the IIEF questionnaire to assess the men's sexual life and erectile function. It should be pointed out that there are other methods to diagnose ED, such as nocturnal penile tumescence (NPT), which should be considered in future studies.

\section{Conclusions}

In the present study lower prevalence of ED and better sexual quality of life were observed in the patients after bariatric surgery. Higher scores in erectile function, sexual desire and overall satisfaction domains reflects better sexual functioning in post-bariatric patients. The IIEF and SQoL-M scores were not dependent on the type of surgery. The IIEF and EF scores predicted the SQoL-M score. The improvement in male sexual function may be considered as an advantage of surgical weight loss.

\section{Conflict of interest}

The authors declare no conflict of interest.

\section{References}

1. Lipowicz A, Łopuszańska M, Kołodziej M, et al. Secular trends in $\mathrm{BMI}$ and the prevalence of obesity in young Polish males from 1965 to 2010. Eur J Public Health 2015; 25: 279-82.

2. International Obesity Taskforce (IOTF) Trends in Global obesity. http://www.iaso.org/iotf/obesity/. Accessed 25 May 2015.

3. Han TS, Tajar A, O'Neill TW, et al. Impaired quality of life and sexual function in overweight and obese men: the European Male Ageing Study. Eur J Endocrinol 2011; 164: 1003-11.

4. Park JH, Cho IC, Kim YS, et al. Body mass index, waist-to-hip ratio, and metabolic syndrome as predictors of middle-aged men's health. Korean J Urol 2015; 56: 386-92.

5. Rosenblatt A, Faintuch J, Cecconello I. Abnormalities of reproductive function in male obesity before and after bariatric surgery - a comprehensive review. Obes Surg 2015; 25: 1281-92.

6. Lue TF. Erectile dysfunction. N Engl J Med 2000; 342: 1802-13.

7. Colquitt JL, Pickett K, Loveman E, et al. Surgery for weight loss in adults. Cochrane Database Syst Rev 2014; 8: CD003641.

8. Paluszkiewicz R, Kalinowski P, Wróblewski T, et al. Prospective randomized clinical trial of laparoscopic sleeve gastrectomy versus open Roux-en-Y gastric bypass for the management of patients with morbid obesity. Videosurgery Miniinv 2012; 7 : 225-32.

9. Angrisani L, Santonicola A, Iovino P, et al. Bariatric Surgery Worldwide 2013. Obes Surg 2015; 25: 1822-32.

10. Janik MR, Stanowski E, Paśnik K, Janik MR. Present status of bariatric surgery in Poland. Videosurgery Miniinv 2016; 11: 22-5.
11. Hess DS, Hess DW. Biliopancreatic diversion with a duodenal switch. Obes Surg 1998; 8: 267-82.

12. Wittgrove AC, Clark GW, Tremblay LJ. Laparoscopic gastric bypass, Roux-en-Y: preliminary report of five cases. Obes Surg 2014; 4: 353-7.

13. Maggard MA, Shugarman LR, Suttorp M, et al. Meta-analysis: surgical treatment of obesity. Ann Intern Med 2005; 142: 547-59.

14. Major P, Matłok M, Pędziwiatr M, et al. Quality of life after bariatric surgery. Obes Surg 2015; 25: 1703-10.

15. Fried M, Yumuk V, Oppert JM, et al. Interdisciplinary European guidelines on metabolic and bariatric surgery. Obes Facts 2013; 6: 449-68.

16. Rosen RC, Riley A, Wagner G, et al. The International Index of Erectile Function (IIEF): a multidimensional scale for assessment of erectile dysfunction. Urology 1997; 49: 822-30.

17. Cappelleri JC, Rosen RC, Smith MD, et al. Some developments on the International Index of Erectile Function (IIEF). Drug Info J 1999; 33: 179-90.

18. Cappelleri JC, Siegel RL, Osterloh IH, et al. Relationship between patient self-assessment of erectile function and the erectile function domain of the International Index of Erectile Function. Urology 2000; 56: 477-81.

19. Jardin A, Wagner G, Khoury S, et al. Erectile dysfunction: 1st international consultation on erectile dysfunction. Health Publications Plymouth, UK 2000; 718-9.

20. Rosen RC, Cappelleri JC, Gendrano N. The International Index of Erectile Function (IIEF): a state-of-the-science review. Int J Impot Res 2002; 14: 226-44.

21. Abraham L, Symonds T, Morris MF. Psychometric validation of a sexual quality of life questionnaire for use in men with premature ejaculation or erectile dysfunction. J Sex Med 2008; 5 : 595-601.

22. Janik MR, Bielecka I, Paśnik K, et al. Female sexual function before and after bariatric surgery: a cross-sectional study and review of literature. Obes Surg 2015; 25: 1511-7.

23. Efthymiou V, Hyphantis T, Karaivazoglou K, et al. The effect of bariatric surgery on patient HRQOL and sexual health during a 1-year postoperative period. Obes Surg 2015; 25: 310-8.

24. Rosenblatt A, Faintuch J, Cecconello I. Sexual hormones and erectile function more than 6 years after bariatric surgery. Surg Obes Relat Dis 2013; 9: 636-40.

25. Reis LO, Zani EL, Saad RD, et al. A. Bariatric surgery does not interfere with sperm quality - a preliminary long-term study. Reprod Sci 2012; 19: 1057-62.

26. Reis LO, Favaro WJ, Barreiro GC, et al. Erectile dysfunction and hormonal imbalance in morbidly obese male is reversed after gastric bypass surgery: a prospective randomized controlled trial. Int J Androl 2010; 33: 736-44

27. Mora M, Aranda GB, de Hollanda A, et al. Weight loss is a major contributor to improved sexual function after bariatric surgery. Surg Endosc 2013; 27: 3197-204.

28. Groutz A, Gordon D, Schachter P, et al. Effects of bariatric surgery on male lower urinary tract symptoms and sexual function. Neurourol Urodyn 2016 Feb 16. doi: 10.1002/nau.22980.

Received: 10.07.2016, accepted: 21.08.2016. 